Article

\title{
Emerging Presence of Culturable Microorganisms in Clinical Samples of the Genitourinary System: Systematic Review and Experience in Specialized Care of a Regional Hospital
}

\author{
Antonio Rosales-Castillo ${ }^{1,2}$, Gemma Jiménez-Guerra ${ }^{3}{ }^{\circledR}$, Lara Ruiz-Gómez ${ }^{4}$, Manuela Expósito-Ruíz ${ }^{5} \mathbb{D}^{\mathbb{B}}$, \\ José María Navarro-Marí ${ }^{3}\left(\mathbb{D}\right.$ and José Gutiérrez-Fernández ${ }^{2,3,4, *(\mathbb{D})}$
}

Citation: Rosales-Castillo, A.; Jiménez-Guerra, G.; Ruiz-Gómez, L.; Expósito-Ruíz, M.; Navarro-Marí, J.M.; Gutiérrez-Fernández, J. Emerging Presence of Culturable Microorganisms in Clinical Samples of the Genitourinary System:

Systematic Review and Experience in Specialized Care of a Regional

Hospital. J. Clin. Med. 2022, 11, 1348. https://doi.org/10.3390/jcm11051348

Academic Editor: Emilio Sacco

Received: 25 January 2022

Accepted: 26 February 2022

Published: 1 March 2022

Publisher's Note: MDPI stays neutral with regard to jurisdictional claims in published maps and institutional affiliations.

Copyright: (c) 2022 by the authors. Licensee MDPI, Basel, Switzerland. This article is an open access article distributed under the terms and conditions of the Creative Commons Attribution (CC BY) license (https:// creativecommons.org/licenses/by/ $4.0 /$ )
1 Servicio de Medicina Interna, Virgen de las Nieves University Hospital \& Instituto de Investigación Biosanitaria de Granada (ibs.GRANADA), Avenida de las Fuerzas Armadas 2, 18014 Granada, Spain; anrocas90@hotmail.com

2 Program in Clinical Medicine and Public Health, University of Granada \& Instituto de Investigación Biosanitaria de Granada (ibs.GRANADA), 18016 Granada, Spain

3 Laboratory of Microbiology, Virgen de las Nieves University Hospital \& Instituto de Investigación Biosanitaria de Granada (ibs.GRANADA), Avenida de las Fuerzas Armadas 2, 18014 Granada, Spain; bobdiegjg@gmail.com (G.J.-G.); josem.navarro.sspa@juntadeandalucia.es (J.M.N.-M.)

4 Department of Microbiology, School of Medicine, University of Granada \& Instituto de Investigación Biosanitaria de Granada (ibs.GRANADA), Avenida de la Investigación 11, 18016 Granada, Spain; lararuizgomez@correo.ugr.es

5 Unit of Biostatistics, Department of Statistics, School of Medicine, University of Granada, 18016 Granada, Spain; mexpositoruiz@ugr.es

* Correspondence: josegf@ugr.es

Abstract: The detection of emerging pathogens responsible for genitourinary infections has increased with technological advances. We conducted a systematic review of publications on the involvement of these microorganisms in genitourinary samples, and we also investigated their presence and antibiotic susceptibility in samples from patients at our regional hospital (Granada, Spain). The MEDLINE database was searched up to 31 December 2020, and a cross-sectional descriptive study was performed of results obtained in urine samples and genital exudates from January 2016 through December 2019. The review highlighted the frequent involvement of Neisseria meningitidis in genital infections, while the data on other microorganisms were consistent with findings in our patient series. The emerging microorganisms most often responsible for urinary tract infections were Streptococcus bovis $(58.5 \%)$ and Gardnerella vaginalis (23.6\%) in females, and S. bovis (32.3\%), Aerococcus urinae (18.6\%), and Corynebacterium spp. (16.9\%) in males; those most frequently reported in genital infections were S. viridans (36.4\%) in females and C. glucuronolyticum (32.2\%) and G. vaginalis (35.6\%) in males. In general, emerging pathogens are resistant to conventional antibiotics such as penicillin. However, there has also been an increase in beta-lactam resistance by the $S$. bovis group and Corynebacterium spp. The systematic review showed that emerging microorganisms are responsible for only a small percentage of genitourinary infections but are of major clinical interest, with a predominance of the S. bovis group, G. vaginalis, Lactobacillus spp., Aerococcus spp., and Corynebacterium spp. in urine samples and of G. vaginalis and C. glucuronolyticum in genital samples. Given the increasing resistance to antibiotics empirically prescribed in patients with genitourinary infections, it is recommended to create an antibiogram in all cases.

Keywords: urinary tract infection; emerging pathogens; cervix bacteria; vaginitis bacteria; balano-posthitis bacteria; prostatitis bacteria; epididymitis bacteria; urethritis bacteria

\section{Introduction}

Genitourinary infections are among the most frequent infections worldwide and are responsible for a large percentage of hospital and primary care consultations, and a delay in their correct diagnosis and treatment can sometimes have serious consequences 
for patients. The microbiological agents most widely considered in diagnostic protocols are Enterobacteriaceae, enterococci, Pseudomonas spp., Acinetobacter spp., and Candida spp. However, major technological advances now permit the detection of microbiological agents that had not previously been identified as responsible for infections and whose cultures had tested negative, resulting in the prescription of non-targeted broad spectrum empirical antibiotics.

The capacity to identify these less well-known agents allows an antibiogram to be created, which is of major clinical relevance because of their resistance to the antibiotics most often empirically prescribed in this type of infection (e.g., quinolones and fosfomycin). This allows the selection of a targeted antibiotic treatment, with the associated microbiological and ecological advantages. Early descriptions in the literature of infrequent microorganisms involved in cases of cystitis and prostatitis [1-4] have been followed by an increasing number of reports as microbiological techniques and culture methods have improved. There are various possible explanations for the failure to consider these microorganisms, including their misclassification due to the absence of distinctive phenotypic criteria or the misinterpretation of significant growth as "contamination by microbiota", and their non-detection by standard methods due to their slow growth and the need for nutritionally enriched culture media [5]. They include Corynebacterium spp., Aerococcus spp., Actinotignum spp., Lactobacillus spp., Streptococcus bovis (SBG) and viridans (SVG) groups, Facklamia spp., Pasteurella spp., Neisseria meningitidis, and Gardnerella vaginalis. Their development and emergence in genitourinary tract infections have been favored by multiple social factors, including the early initiation of sexual relations by adolescents, among other societal trends. They are of particular concern because they can arise in the absence of the pathogens habitually associated with genitourinary tract infections and are increasingly frequent in older populations with more concomitant diseases. Given the lack of information in the literature on these microorganisms and the increase in their detection through improved clinical microbiology techniques, studies are needed to update diagnostic and therapeutic protocols accordingly. Hence, the objective of this study was to analyze the presence of infrequent microorganisms in genitourinary samples through a systematic review of the literature and a study of the microorganisms detected in our regional hospital and their antibiotic susceptibility.

\section{Material and Methods}

\subsection{Systematic Review}

The MEDLINE database was searched for relevant publications up to 31 December 2020. The terms "urinary tract infection" and "emergent pathogens" were used in an open search and the terms cervix bacteria, vaginitis bacteria, balanitis bacteria, posthitis bacteria, prostatitis bacteria, epididymitis bacteria, and urethritis bacteria in an open search filtered by "Case Report" and "Letter". Review exclusion criteria were: studies on microorganisms habitually involved in genitourinary infections (Enterobacteriaceae, glucose non-fermenting gram-negative bacilli, Candida spp., or Hemophilus spp.); studies on Staphylococcus spp. And some Streptococcus spp., including only SBG, SVG, and Streptococcus pneumoniae; studies on microorganisms responsible for sexually transmitted infections; studies that did not report on the relationship of microorganisms with a clinical situation, and studies that were not published in English or Spanish. The references of all studies were reviewed to complete the search.

\subsection{Study of Suspected Clinical Episodes}

A cross-sectional descriptive study was performed on microbiology laboratory results obtained in samples from patients suspected of genitourinary system infection attended between 1 January 2016 and 31 December 2019 by specialist, emergency, and outpatient care departments of the Virgen de las Nieves University Hospital in Granada (Spain), a regional specialist center serving over 330,000 inhabitants. No exclusion criteria were 
applied, except for the exclusion of duplicates and repeat microbiological studies of the same episode.

Urine samples from patients suspected of urinary tract infection (UTI) were gathered from mid-stream micturition, permanent catheterization, provisional catheterization, pediatric urine collection bag, or nephrostomy catheter under anti-contamination conditions and were processed as previously described, using a 1- $\mu \mathrm{L}$ calibrated loop and UriSelect 4 chromogenic culture medium (Bio-Rad, Barcelona, Spain) incubated for $24 \mathrm{~h}$ at $37^{\circ} \mathrm{C}$. In samples from the Nephrology Department alone, a lamb blood agar plate (BectonDickinson, Madrid, Spain) was added and incubated in $\mathrm{CO}_{2}$. Cutoff points for colony growth were: Negative $(<10,000 \mathrm{UFC} / \mathrm{mL}$ and $<1000 \mathrm{UFC} / \mathrm{mL}$ in urine from provisional catheterization); Positive (bacteriuria $>100,000 \mathrm{UFC} / \mathrm{mL}$ of one or two uropathogens, or between 10,000 and 100,000 of one alone; and $>10,000 \mathrm{UFC} / \mathrm{mL}$ of one or two uropathogens, or between 1000 and $10,000 \mathrm{UFC} / \mathrm{mL}$ of one alone in urine from provisional catheterization); or Mixed ( $>10,000 \mathrm{UFC} / \mathrm{mL}$ of more than two uropathogens).

Semen, glans, endocervical, genital ulcer and urethral exudate samples from patients suspected of genital system infection were processed as previously described, using real-time multiplex PCR to investigate the presence of C. trachomatis, N. gonorrhoeae, T. vaginalis (BD MAX CT/GC/TV BD, Franklin Lakes, NJ, USA), Mycoplasma genitalium, Mycoplasma hominis, and Ureaplasma urealyticum (BD MAX System, BioGX DNA, 350-011A-MAX, Amsterdam, The Netherlands). In samples of vulvovaginal exudates, DNA hybridization tests were used to detect G. vaginalis, Candida spp., and trichomonas (BD AFFIRM VPIII, BD, Madrid, Spain) in a BD MicroProbe Processor, and they were also seeded on blood agar (Becton-Dickinson), chocolate agar (Becton-Dickinson), Martin-Lewis agar (Becton-Dickinson) media for N. gonorrhoeae and on Chromogenic agar medium for Candida spp. (BIO-RAD). Results were considered significant when there was monomicrobial and abundant growth (up to the third seeding area) of an opportunistic pathogen or the presence of a strict pathogen. The presence of $M$. hominis and $U$. urealyticum was indicated when the study yielded a value of $\mathrm{Ct} \leq 30$. More information on the sensitivity of the PCR system to detect mycoplasmas and ureaplasmas is available from the manufacturer (https:/ / drive.google.com/drive/folders/1KuQwlMsrmBlQx_3ftQHc4T3re1ZdO_tk (accessed on 30 November 2021)). Given that a value of $\mathrm{Ct} \leq 30$ indicates a higher microorganism concentration and M. hominis and Ureaplasma spp. Can be potential colonizers, these were only reported in samples with this result.

Optimal identification of the isolated microorganisms was performed using MALDITOF mass spectrometry (Biotyper, Brucker Daltonics, Billerica, MA, USA) and/or MicroScan Walkaway (Beckman-Coulter, Brea, CA, USA). The susceptibility study was conducted by broth microdilution using the automated MicroScan Walkaway system for SBG and diffusion gradient strips (MIC Test Strip, Liofilchem, Italy) for the remaining microorganisms, as recommended by the European Committee on Antimicrobial Susceptibility Testing (EUCAST) (https:/ / eucast.org/ (accessed on 30 November 2021)) [6] and/or Clinical and Laboratory Standards Institute (CLSI) (https: / / clsi.org/ (accessed on 30 November 2021)) [7] for the year of isolation. In the absence of reference data, use was made of interpretation criteria for microorganisms that are similar in respiratory metabolism, Gram staining behavior, and growth rate. Isolated microorganisms were classified in the laboratory reports as susceptible, intermediate, or resistant to tested antibiotics, accompanied by a request for clinical assessment of the report.

Data were gathered from the Andalusian public health laboratory computer system (MODULAB ${ }^{\circledR}$ ) on type of sample, origin, microorganism, and patient sex and age for their anonymized evaluation. The microorganisms excluded from the literature search (see above) were also excluded from this study (Enterobacteriaceae, glucose nonfermenting gram-negative bacilli, Candida spp., Hemophilus spp., Staphylococcus spp., selected Streptococcus spp., and microorganisms producing sexually transmitted infections). Episodes in which the microorganism of interest was isolated alongside another microorganism were also excluded, given the impossibility of distinguishing the one responsible 
for the associated disease. The objectives were to evaluate the results obtained for monomicrobial culturable microorganisms with an abundant and significant presence and to determine the rate of emerging pathogens in genitourinary system infections at our hospital from 2016 through 2019. In a descriptive analysis, absolute and relative frequencies were calculated for each type of sample, grouped by microorganism. The relationship between the presence of microorganisms and age or sex was evaluated using Pearson's chi-square test or Fisher's test (when no more than $20 \%$ of cells had expected frequencies $<5$ ), considering $p<0.05$ as significant. Finally, the susceptibility of microorganisms to antibiotics was calculated by clinical category. IBM SPSS Statistics 19 was used for data analyses. Adequate clinical information was not available to analyze factors associated with the presence of a given microorganism.

\section{Results}

\subsection{Systematic Review}

The search of the literature yielded 54 items on emerging microorganisms in genitourinary samples (see Tables 1-3 and S1). The most frequently reported UTI-producing microorganisms were Corynebacterium spp., Aerococcus spp., and Actinotignum spp. (Table 1) The most frequently reported urethritis-producing microorganism in males were Neisseria meningitides (15 cases), Corynebacterium spp., and Streptococcus spp. (Table 2). In genital episodes other than urethritis, the most frequent were N. meningitidis and Actinotignum schaalii, with three cases each (Table 3).

Table 1. Articles in the systematic review on emerging microorganisms in urinary tract infections.

\begin{tabular}{|c|c|c|c|c|c|c|c|}
\hline Article & Age-Sex & $\begin{array}{l}\text { Predisposing } \\
\text { Factors }\end{array}$ & Microorganism & $\begin{array}{c}\text { Clinical } \\
\text { Manifestations }\end{array}$ & $\begin{array}{l}\text { Clinical } \\
\text { Sample }\end{array}$ & Treatment & $\begin{array}{l}\text { Microbiological } \\
\text { Identification } \\
\text { Method }\end{array}$ \\
\hline $\begin{array}{l}\text { Vedel G et al., } \\
2006\end{array}$ & 64-Male & $\begin{array}{l}\text { Recurrent } \\
\text { urolithiasis }\end{array}$ & $\begin{array}{l}\text { Corynebacterium } \\
\text { pseudogenitalium }\end{array}$ & $\begin{array}{l}\text { Urinary tract } \\
\text { infection }\end{array}$ & Urine & Norfloxacin & $\begin{array}{c}\text { RNAr 16S } \\
\text { gene sequencing }\end{array}$ \\
\hline $\begin{array}{l}\text { El Sayegh } \\
\text { H et al., } 2007\end{array}$ & 61-Male & $\begin{array}{l}\text { Vesicocutaneous } \\
\text { fistula }\end{array}$ & $\begin{array}{c}\text { Corynebacterium } \\
\text { urealyticum }\end{array}$ & Cystitis & Urine & Quinolones & Not described \\
\hline $\begin{array}{l}\text { Perciaccante } \\
\text { A et al., } 2007\end{array}$ & 57-Male & $\begin{array}{l}\text { Systemic lupus } \\
\text { erythematosus } \\
\text { Left obstructive } \\
\text { uropathy with } \\
\text { hydronephrosis }\end{array}$ & $\begin{array}{l}\text { Corynebacterium } \\
\text { urealyticum }\end{array}$ & Cystitis & Urine & Teicoplanin & Not described \\
\hline $\begin{array}{l}\text { Beteta A et al., } \\
2009\end{array}$ & 34-Female & Not described & $\begin{array}{l}\text { Corynebacterium } \\
\text { striatum }\end{array}$ & $\begin{array}{l}\text { Urinary tract } \\
\text { infection }\end{array}$ & Urine & Ciprofloxacin & $\begin{array}{l}\text { API Coryne } \\
\text { (BioMérieux) }\end{array}$ \\
\hline $\begin{array}{l}\text { Larios OE et al., } \\
2010\end{array}$ & 76-Female & $\begin{array}{l}\text { Recurrent } \\
\text { urinary tract } \\
\text { infection }\end{array}$ & $\begin{array}{l}\text { Actinotignum } \\
\text { schaalii }\end{array}$ & $\begin{array}{l}\text { Urinary tract } \\
\text { infection }\end{array}$ & Urine & Clindamycin & Not described \\
\hline $\begin{array}{l}\text { Zimmermann } \\
\text { P et al., } 2012\end{array}$ & 8-Male & $\begin{array}{l}\text { Neurogenic } \\
\text { bladder } \\
\text { dysfunction }\end{array}$ & $\begin{array}{l}\text { Actinotignum } \\
\text { schaalii }\end{array}$ & $\begin{array}{l}\text { Urinary tract } \\
\text { infection }\end{array}$ & Urine & $\begin{array}{l}\text { Trimethoprim- } \\
\text { Sulfamethoxazo-le } \\
\text { Amoxicilin }\end{array}$ & $\begin{array}{c}\text { RNAr 16S } \\
\text { gene sequencing }\end{array}$ \\
\hline $\begin{array}{c}\text { Barberis C et al., } \\
2018\end{array}$ & 36-Female & $\begin{array}{l}\text { Chronic renal } \\
\text { failure }\end{array}$ & $\begin{array}{c}\text { Corynebacterium } \\
\text { coyleae }\end{array}$ & $\begin{array}{l}\text { Urinary tract } \\
\text { infection }\end{array}$ & Urine & $\begin{array}{l}\text { Piperacillin/ } \\
\text { tazo-bactam } \\
\text { Ciprofloxacin }\end{array}$ & $\begin{array}{c}\text { MALDI-TOF } \\
\text { PCR amplification } \\
\text { rpoB gene } \\
\text { sequence analysis }\end{array}$ \\
\hline \multirow{2}{*}{$\begin{array}{l}\text { Jiménez G et al., } \\
2018\end{array}$} & 80-Male & $\begin{array}{l}\text { Benign prostate } \\
\text { hypertrophy }\end{array}$ & $\begin{array}{l}\text { Aerococcus } \\
\text { sanguinicola }\end{array}$ & $\begin{array}{c}\text { Urinary septic } \\
\text { shock } \\
\text { Kidney failure }\end{array}$ & Urine & $\begin{array}{l}\text { Amoxicilin- } \\
\text { clavulanic acid }\end{array}$ & $\begin{array}{c}\text { MALDI-TOF } \\
\text { RNAr 16S } \\
\text { gene sequencing }\end{array}$ \\
\hline & 88-Male & Not described & $\begin{array}{l}\text { Aerococcus } \\
\text { sanguinicola }\end{array}$ & $\begin{array}{l}\text { Urinary tract } \\
\text { infection }\end{array}$ & Urine & Cefuroxime & $\begin{array}{c}\text { MALDI-TOF } \\
\text { RNAr 16S } \\
\text { gene sequencing }\end{array}$ \\
\hline $\begin{array}{l}\text { Lorenzin G et al., } \\
\qquad 2018\end{array}$ & 69-Male & $\begin{array}{c}\text { Type } 2 \\
\text { diabetes mellitus } \\
\text { Terminal renal } \\
\text { disease } \\
\text { Other } \\
\text { comorbidities }\end{array}$ & $\begin{array}{c}\text { Myroides } \\
\text { odoratimimus }\end{array}$ & $\begin{array}{l}\text { Urinary tract } \\
\text { infection }\end{array}$ & Urine & $\begin{array}{l}\text { Trimethoprim- } \\
\text { Sulfamethoxazo-le }\end{array}$ & $\begin{array}{c}\text { MALDI-TOF } \\
\text { RNAr 16S } \\
\text { gene sequencing }\end{array}$ \\
\hline
\end{tabular}


Table 1. Cont.

\begin{tabular}{|c|c|c|c|c|c|c|c|}
\hline Article & Age-Sex & $\begin{array}{l}\text { Predisposing } \\
\text { Factors }\end{array}$ & Microorganism & $\begin{array}{c}\text { Clinical } \\
\text { Manifestations }\end{array}$ & $\begin{array}{l}\text { Clinical } \\
\text { Sample }\end{array}$ & Treatment & $\begin{array}{l}\text { Microbiological } \\
\text { Identification } \\
\text { Method }\end{array}$ \\
\hline $\begin{array}{l}\text { Figueroa F et al., } \\
2019\end{array}$ & 55-Male & Not described & Aerococcus urinae & $\begin{array}{c}\text { Urinary tract } \\
\text { infection Mitral } \\
\text { valve } \\
\text { endocarditis }\end{array}$ & $\begin{array}{l}\text { Urine } \\
\text { Blood }\end{array}$ & $\begin{array}{l}\text { Gentamicin } \\
\text { Penicillin G }\end{array}$ & Not described \\
\hline $\begin{array}{l}\text { Pichon M et al., } \\
2019\end{array}$ & 67-Female & $\begin{array}{l}\text { Neurogenic } \\
\text { bladder } \\
\text { Recurrent } \\
\text { urinary tract } \\
\text { infection }\end{array}$ & $\begin{array}{c}\text { Corynebacterium } \\
\text { riegelii }\end{array}$ & Urinary sepsis & $\begin{array}{l}\text { Urine } \\
\text { Blood }\end{array}$ & $\begin{array}{l}\text { Amoxicilin } \\
\text { Gentamicin }\end{array}$ & MALDI-TOF \\
\hline $\begin{array}{l}\text { Napolitani M } \\
\text { et al., } 2019\end{array}$ & 20-Male & $\begin{array}{l}\text { Suprapubic } \\
\text { catheter }\end{array}$ & Kocuria kristinae & $\begin{array}{l}\text { Urinary tract } \\
\text { infection }\end{array}$ & Not described & Not described & Not described \\
\hline
\end{tabular}

Table 2. Articles in the systematic review on emerging microorganisms in urethritis.

\begin{tabular}{|c|c|c|c|c|c|c|c|}
\hline Article & Age-Sex & $\begin{array}{l}\text { Predisposing } \\
\text { Factors }\end{array}$ & Microorganism & $\begin{array}{c}\text { Clinical } \\
\text { Manifestations }\end{array}$ & $\begin{array}{l}\text { Clinical } \\
\text { Sample }\end{array}$ & Treatment & $\begin{array}{l}\text { Microbiological } \\
\text { Identification } \\
\text { Method }\end{array}$ \\
\hline $\begin{array}{c}\text { Gregory JE et al., } \\
1979\end{array}$ & 27-Male & Alcohol abuse & $\begin{array}{l}\text { Neisseria } \\
\text { meningitidis }\end{array}$ & Urethritis & $\begin{array}{l}\text { Urethral } \\
\text { exudate }\end{array}$ & $\begin{array}{l}\text { Procaine penicillin } \\
\text { Probenecid }\end{array}$ & Not described \\
\hline $\begin{array}{c}\text { Karolus JJ et al., } \\
1980\end{array}$ & 29-Male & $\begin{array}{l}\text { Oral-genital and } \\
\text { vaginal contact }\end{array}$ & $\begin{array}{l}\text { Neisseria } \\
\text { meningitidis }\end{array}$ & Urethritis & $\begin{array}{l}\text { Urethral } \\
\text { exudate }\end{array}$ & Procaine penicillin & Not described \\
\hline $\begin{array}{c}\text { Chowdhury } \\
\text { MNH et al., } 1984\end{array}$ & 35-Male & $\begin{array}{l}\text { Sexual relations } \\
\text { with female } \\
\text { partner (non- } \\
\text { extramarital, } \\
\text { oral-genital, } \\
\text { or anal) }\end{array}$ & $\begin{array}{l}\text { Streptococcus } \\
\text { group } B\end{array}$ & Urethritis & $\begin{array}{l}\text { Urethral } \\
\text { exudate }\end{array}$ & $\begin{array}{l}\text { Phenoxymethy- } \\
\text { lpenicillin }\end{array}$ & Not described \\
\hline $\begin{array}{l}\text { Noble RC et al., } \\
1985\end{array}$ & 25-Male & $\begin{array}{l}\text { Vaginal and oral } \\
\text { sexual relation } \\
\text { with a female }\end{array}$ & $\begin{array}{l}\text { Streptococcus } \\
\text { pneumoniae }\end{array}$ & Urethritis & $\begin{array}{l}\text { Urethral } \\
\text { exudate }\end{array}$ & $\begin{array}{l}\text { Ampicillin } \\
\text { Probenecid }\end{array}$ & Not described \\
\hline $\begin{array}{l}\text { Hay PE et al., } \\
1989\end{array}$ & 16-Male & Oral sex (female) & $\begin{array}{l}\text { Neisseria } \\
\text { meningitidis }\end{array}$ & Urethritis & $\begin{array}{l}\text { Urethral } \\
\text { exudate }\end{array}$ & $\begin{array}{l}\text { Spectinomycin } \\
\text { Doxycycline }\end{array}$ & Not described \\
\hline $\begin{array}{l}\text { Wilson APR } \\
\text { et al., } 1989\end{array}$ & 18-Male & $\begin{array}{l}\text { Sexual relations } \\
\text { with steady } \\
\text { partner (female) }\end{array}$ & $\begin{array}{l}\text { Neisseria } \\
\text { meningitidis }\end{array}$ & Urethritis & $\begin{array}{l}\text { Urethral } \\
\text { exudate }\end{array}$ & $\begin{array}{l}\text { Ampicillin } \\
\text { Probenecid }\end{array}$ & Not described \\
\hline $\begin{array}{c}\text { Phillips EA et al., } \\
1989\end{array}$ & 19-Male & $\begin{array}{l}\text { Sexual contact } \\
\text { (female) }\end{array}$ & $\begin{array}{l}\text { Neisseria } \\
\text { meningitidis }\end{array}$ & Urethritis & $\begin{array}{l}\text { Urethral } \\
\text { exudate }\end{array}$ & $\begin{array}{l}\text { Amoxicillin } \\
\text { Doxycycline }\end{array}$ & Not described \\
\hline $\begin{array}{c}\text { Shanmugaratnam } \\
\text { K et al., } 1989\end{array}$ & 25-Male & $\begin{array}{l}\text { Oral-genital } \\
\text { contact }\end{array}$ & $\begin{array}{c}\text { Neisseria } \\
\text { meningitidis }\end{array}$ & Urethritis & $\begin{array}{l}\text { Urethral } \\
\text { exudate }\end{array}$ & Ciprofloxacin & Not described \\
\hline $\begin{array}{c}\text { Faigel HC et al., } \\
1990\end{array}$ & 20-Male & $\begin{array}{c}\text { Oral-genital } \\
\text { contact (female) }\end{array}$ & $\begin{array}{l}\text { Neisseria } \\
\text { meningitidis }\end{array}$ & Urethritis & $\begin{array}{l}\text { Urethral } \\
\text { exudate }\end{array}$ & Not described & Not described \\
\hline $\begin{array}{c}\text { Coker DM et al., } \\
1991\end{array}$ & 36-Male & $\begin{array}{l}\text { Sporadic sexual } \\
\text { relations } \\
\text { (female) }\end{array}$ & $\begin{array}{l}\text { Moraxella } \\
\text { urethralis }\end{array}$ & Urethritis & $\begin{array}{l}\text { Urethral } \\
\text { exudate }\end{array}$ & Ciprofloxacin & Not described \\
\hline $\begin{array}{c}\text { Quarto M et al., } \\
1991\end{array}$ & 35-Male & $\begin{array}{l}\text { Occasional oral } \\
\text { sex with a female }\end{array}$ & $\begin{array}{l}\text { Neisseria } \\
\text { meningitidis }\end{array}$ & Urethritis & $\begin{array}{l}\text { Urethral } \\
\text { exudate }\end{array}$ & Ampicillin & Not described \\
\hline $\begin{array}{l}\text { Kanemitsu N } \\
\text { et al., } 2003\end{array}$ & 48-Male & $\begin{array}{l}\text { Oral-genital } \\
\text { contact }\end{array}$ & $\begin{array}{l}\text { Neisseria } \\
\text { meningitidis }\end{array}$ & Urethritis & $\begin{array}{l}\text { Urethral } \\
\text { exudate }\end{array}$ & Levofloxacin & Enzymatic profiles \\
\hline $\begin{array}{l}\text { Orden B et al., } \\
2004\end{array}$ & 36-Male & $\begin{array}{l}\text { Unprotected oral } \\
\text { and vaginal } \\
\text { sexual relations }\end{array}$ & $\begin{array}{c}\text { Neisseria } \\
\text { meningitidis }\end{array}$ & Urethritis & $\begin{array}{l}\text { Urethral } \\
\text { exudate }\end{array}$ & $\begin{array}{l}\text { Ceftriaxone } \\
\text { Doxycycline }\end{array}$ & $\begin{array}{c}\text { API NH } \\
\text { (bioMérieux) }\end{array}$ \\
\hline $\begin{array}{l}\text { Rodríguez CN } \\
\text { et al., } 2005\end{array}$ & 27-Male & $\begin{array}{l}\text { Oral and vaginal } \\
\text { sexual relations } \\
\text { with several } \\
\text { women }\end{array}$ & $\begin{array}{l}\text { Neisseria } \\
\text { meningitidis }\end{array}$ & Urethritis & $\begin{array}{l}\text { Urethral } \\
\text { exudate }\end{array}$ & $\begin{array}{l}\text { Ceftriaxone } \\
\text { Doxycycline }\end{array}$ & $\begin{array}{c}\text { API NH } \\
\text { (bioMérieux) }\end{array}$ \\
\hline $\begin{array}{l}\text { Urra E et al., } \\
2005\end{array}$ & 38-Male & $\begin{array}{l}\text { Sexual relations } \\
\text { with steady } \\
\text { partner (female) }\end{array}$ & $\begin{array}{l}\text { Neisseria } \\
\text { meningitidis }\end{array}$ & Urethritis & $\begin{array}{l}\text { Urethral } \\
\text { exudate }\end{array}$ & Minocycline & $\begin{array}{c}\text { API NH } \\
\text { (bioMérieux) }\end{array}$ \\
\hline $\begin{array}{l}\text { Abdolrasouli A } \\
\text { et al., } 2007\end{array}$ & 23-Male & $\begin{array}{l}\text { Unprotected } \\
\text { fellatio }\end{array}$ & $\begin{array}{l}\text { Moraxella } \\
\text { catarrhalis }\end{array}$ & Urethritis & $\begin{array}{l}\text { Urethral and } \\
\text { throat exudate }\end{array}$ & Ciprofloxacin & Not described \\
\hline $\begin{array}{c}\text { Koroglu M et al., } \\
2007\end{array}$ & 43-Male & $\begin{array}{l}\text { Multiple sexual } \\
\text { partners }\end{array}$ & $\begin{array}{l}\text { Streptococcus } \\
\text { pneumoniae }\end{array}$ & Urethritis & $\begin{array}{l}\text { Urethral } \\
\text { exudate }\end{array}$ & Amoxicillin & BD BBL Crystal test \\
\hline
\end{tabular}


Table 2. Cont.

\begin{tabular}{|c|c|c|c|c|c|c|c|}
\hline Article & Age-Sex & $\begin{array}{l}\text { Predisposing } \\
\text { Factors }\end{array}$ & Microorganism & $\begin{array}{c}\text { Clinical } \\
\text { Manifestations }\end{array}$ & $\begin{array}{l}\text { Clinical } \\
\text { Sample }\end{array}$ & Treatment & $\begin{array}{l}\text { Microbiological } \\
\text { Identification } \\
\text { Method }\end{array}$ \\
\hline $\begin{array}{l}\text { Galán-Sánchez F } \\
\text { et al., } 2011\end{array}$ & 18-Male & $\begin{array}{l}\text { Sexual relations } \\
\text { with multiple } \\
\text { partners }\end{array}$ & $\begin{array}{l}\text { Corynebacterium } \\
\text { glucuronolyticum }\end{array}$ & Urethritis & $\begin{array}{l}\text { Urethral } \\
\text { exudate }\end{array}$ & Ciprofloxacin & API Coryne sistem \\
\hline $\begin{array}{l}\text { Katz AR et al., } \\
2011\end{array}$ & 26-Male & $\begin{array}{l}\text { Oral and vaginal } \\
\text { sex with } \\
\text { one woman }\end{array}$ & $\begin{array}{l}\text { Neisseria } \\
\text { meningitidis }\end{array}$ & Urethritis & $\begin{array}{l}\text { Urethral } \\
\text { exudate }\end{array}$ & $\begin{array}{c}\text { Cefixime } \\
\text { Azithromycin }\end{array}$ & $\begin{array}{c}\text { API NH } \\
\text { (bioMérieux) }\end{array}$ \\
\hline $\begin{array}{l}\text { Bousquet A et al., } \\
2012\end{array}$ & 35-Male & $\begin{array}{l}\text { Unprotected } \\
\text { oral-genital sex } \\
\text { with males } \\
\text { and females }\end{array}$ & $\begin{array}{l}\text { Neisseria } \\
\text { meningitidis }\end{array}$ & Urethritis & $\begin{array}{l}\text { Urethral } \\
\text { exudate }\end{array}$ & $\begin{array}{l}\text { Ceftriaxone } \\
\text { Azithromycin }\end{array}$ & MALDI-TOF \\
\hline $\begin{array}{l}\text { Abdolrasouli A } \\
\text { et al., } 2013\end{array}$ & 27-Male & $\begin{array}{c}\text { Possible } \\
\text { unprotected } \\
\text { sexual relations }\end{array}$ & $\begin{array}{c}\text { Corynebacterium } \\
\text { propinquum }\end{array}$ & Urethritis & $\begin{array}{l}\text { Urethral } \\
\text { exudate }\end{array}$ & $\begin{array}{l}\text { Azithromycin } \\
\text { Vancomycin }\end{array}$ & $\begin{array}{l}\text { API Coryne system } \\
\text { (bioMérieux) }\end{array}$ \\
\hline $\begin{array}{c}\text { Babics A et al., } \\
2015\end{array}$ & 36-Male & Not described & $\begin{array}{l}\text { Gardnerella } \\
\text { vaginalis }\end{array}$ & Urethritis & $\begin{array}{l}\text { Urine } \\
\text { Blood }\end{array}$ & $\begin{array}{l}\text { Azithromycin } \\
\text { Ceftriaxone }\end{array}$ & $\begin{array}{l}\text { MALDI-TOF } \\
\text { (Bruker) }\end{array}$ \\
\hline $\begin{array}{l}\text { Gherardi G et al., } \\
2015\end{array}$ & 37-Male & Not described & $\begin{array}{l}\text { Corynebacterium } \\
\text { glucuronolyticum }\end{array}$ & $\begin{array}{l}\text { Genitourinary } \\
\text { tract infection }\end{array}$ & $\begin{array}{l}\text { Urethral } \\
\text { exudate } \\
\text { Semen } \\
\text { Urine }\end{array}$ & Ciprofloxacin & $\begin{array}{c}\text { MALDI-TOF } \\
\text { RNAr 16S } \\
\text { gene sequencing }\end{array}$ \\
\hline $\begin{array}{l}\text { Seynabou Lo } \\
\text { et al., } 2015\end{array}$ & 52-Male & $\begin{array}{c}\text { Previous } \\
\text { urethroplasties }\end{array}$ & $\begin{array}{l}\text { Corynebacterium } \\
\text { aurimucosum }\end{array}$ & $\begin{array}{l}\text { Urinary tract } \\
\text { infection }\end{array}$ & Urine & Imipenem & MALDI-TOF \\
\hline $\begin{array}{l}\text { Grandolfo M } \\
\text { et al., } 2016\end{array}$ & 39-Male & Not described & $\begin{array}{l}\text { Neisseria elongata } \\
\text { nitroreducens }\end{array}$ & $\begin{array}{c}\text { Purulent } \\
\text { balanoposthitis } \\
\text { Urethritis }\end{array}$ & $\begin{array}{l}\text { Urethral } \\
\text { exudate }\end{array}$ & $\begin{array}{l}\text { Ceftriaxone } \\
\text { Topical mupirocin }\end{array}$ & $\begin{array}{c}\text { Vitek } 2 \text { compact } \\
\text { system } \\
\text { (bioMérieux) }\end{array}$ \\
\hline $\begin{array}{c}\text { Jannic A et al., } \\
2019\end{array}$ & 22-Male & $\begin{array}{l}\text { Sexual relations } \\
\text { with steady } \\
\text { partner (female) }\end{array}$ & $\begin{array}{l}\text { Neisseria } \\
\text { meningitidis }\end{array}$ & Urethritis & $\begin{array}{l}\text { Urethral } \\
\text { exudate }\end{array}$ & $\begin{array}{l}\text { Ceftriaxone } \\
\text { Azithromycin }\end{array}$ & MALDI-TOF \\
\hline
\end{tabular}

Table 3. Articles in the systematic review on emerging microorganisms in episodes other than urethritis.

\begin{tabular}{|c|c|c|c|c|c|c|c|}
\hline Article & Age-Sex & $\begin{array}{l}\text { Predisposing } \\
\text { Factors }\end{array}$ & Microorganism & $\begin{array}{c}\text { Clinical } \\
\text { Manifestations }\end{array}$ & $\begin{array}{l}\text { Clinical } \\
\text { Sample }\end{array}$ & Treatment & $\begin{array}{l}\text { Microbiological } \\
\text { Identification } \\
\text { Method }\end{array}$ \\
\hline \multicolumn{8}{|l|}{ CERVICITIS } \\
\hline $\begin{array}{c}\text { Jaffe LR et al., } \\
1983\end{array}$ & 16-Female & Not described & $\begin{array}{l}\text { Neisseria } \\
\text { meningitidis }\end{array}$ & $\begin{array}{c}\text { Pelvic } \\
\text { inflammatory } \\
\text { disease }\end{array}$ & $\begin{array}{l}\text { Vaginal } \\
\text { exudate }\end{array}$ & $\begin{array}{l}\text { Procaine penicillin } \\
\text { Probenecid } \\
\text { Ampicillin }\end{array}$ & Not described \\
\hline $\begin{array}{c}\text { Quentin R et al., } \\
1991\end{array}$ & 80-Female & $\begin{array}{c}\text { Genital } \\
\text { adenocarcinoma }\end{array}$ & $\begin{array}{l}\text { Pasteurella } \\
\text { multocida }\end{array}$ & $\begin{array}{c}\text { Metrorrhagia } \\
\text { Mucopurulent } \\
\text { vaginal secretion } \\
\text { Occasional fever }\end{array}$ & $\begin{array}{l}\text { Vaginal } \\
\text { exudate }\end{array}$ & $\begin{array}{l}\text { Amoxicillin- } \\
\text { clavulanic acid } \\
\text { Metronidazole }\end{array}$ & Not described \\
\hline $\begin{array}{l}\text { Harriau P et al., } \\
1997\end{array}$ & 19-Female & Pregnancy & $\begin{array}{l}\text { Neisseria } \\
\text { meningitidis }\end{array}$ & $\begin{array}{l}\text { Endocervical } \\
\text { infection }\end{array}$ & $\begin{array}{l}\text { Endocervical } \\
\text { exudate } \\
\text { Urine }\end{array}$ & Amoxicillin & Not described \\
\hline \multicolumn{8}{|l|}{ VAGINITIS } \\
\hline $\begin{array}{l}\text { Greif } Z \text { et al., } \\
1986\end{array}$ & 34-Female & $\begin{array}{l}\text { Contact with } \\
\text { farm parasites } \\
\text { and birds } \\
\text { Pregnancy }\end{array}$ & $\begin{array}{l}\text { Pasteurella } \\
\text { multocida }\end{array}$ & Septicemia & $\begin{array}{c}\text { Blood } \\
\text { Vaginal } \\
\text { exudate }\end{array}$ & $\begin{array}{l}\text { Cephalotin } \\
\text { Tobramycin }\end{array}$ & Not described \\
\hline $\begin{array}{l}\text { Vila de Muga M } \\
\text { et al., } 2008\end{array}$ & 5-Female & Not described & $\begin{array}{l}\text { Streptococcus } \\
\text { pneumoniae }\end{array}$ & $\begin{array}{l}\text { Vaginitis- } \\
\text { peritonitis }\end{array}$ & $\begin{array}{l}\text { Vaginal } \\
\text { exudate }\end{array}$ & $\begin{array}{l}\text { Ceftriaxone } \\
\text { Amoxicillin }\end{array}$ & Not described \\
\hline $\begin{array}{l}\text { Chen X et al., } \\
2015\end{array}$ & 9-Female & Not described & $\begin{array}{l}\text { Corynebaacterium } \\
\text { amycolatum }\end{array}$ & Vaginitis & $\begin{array}{l}\text { Vaginal } \\
\text { exudate }\end{array}$ & $\begin{array}{c}\text { Topical } \\
\text { benzalkonium } \\
\text { chloride } \\
\text { Amoxicillin }\end{array}$ & $\begin{array}{c}\text { Vitek-2 compact } \\
\text { bacterial } \\
\text { identification } \\
\text { system } \\
\text { (bioMérieux) } \\
\text { MALDI-Biotyper }\end{array}$ \\
\hline $\begin{array}{c}\text { Gómez C et al., } \\
2018\end{array}$ & 28-Female & Not described & $\begin{array}{c}\text { Moraxella } \\
\text { osloensis }\end{array}$ & $\begin{array}{l}\text { Tumor in } \\
\text { right groin } \\
\text { Right } \\
\text { adenopathy }\end{array}$ & $\begin{array}{l}\text { Vaginal } \\
\text { exudate }\end{array}$ & Azithromycin & $\begin{array}{c}\text { MALDI-TOF } \\
\text { RNAr 16S } \\
\text { gene sequencing }\end{array}$ \\
\hline
\end{tabular}


Table 3. Cont.

\begin{tabular}{|c|c|c|c|c|c|c|c|}
\hline Article & Age-Sex & $\begin{array}{l}\text { Predisposing } \\
\text { Factors }\end{array}$ & Microorganism & $\begin{array}{c}\text { Clinical } \\
\text { Manifestations }\end{array}$ & $\begin{array}{l}\text { Clinical } \\
\text { Sample }\end{array}$ & Treatment & $\begin{array}{l}\text { Microbiological } \\
\text { Identification } \\
\text { Method }\end{array}$ \\
\hline \multicolumn{8}{|l|}{ BALANITIS } \\
\hline $\begin{array}{l}\text { Grandolfo M } \\
\text { et al., } 2016\end{array}$ & 39-Male & Not described & $\begin{array}{l}\text { Neisseria elongata } \\
\text { nitroreducens }\end{array}$ & $\begin{array}{c}\text { Purulent } \\
\text { balanoposthitis } \\
\text { Urethritis }\end{array}$ & $\begin{array}{l}\text { Urethral } \\
\text { exudate }\end{array}$ & $\begin{array}{c}\text { Ceftriaxone } \\
\text { Topical mupirocin }\end{array}$ & $\begin{array}{c}\text { Vitek } 2 \text { compact } \\
\text { system } \\
\text { (bioMérieux) }\end{array}$ \\
\hline \multicolumn{8}{|l|}{$\begin{array}{l}\text { PROSTATI- } \\
\text { TIS/EPIDIDY- } \\
\text { MITIS } \\
\end{array}$} \\
\hline $\begin{array}{c}\text { Nguyen C et al., } \\
1990\end{array}$ & 39-Male & $\begin{array}{l}\text { Suprapubic } \\
\text { removal of } \\
\text { vesical calculus }\end{array}$ & $\begin{array}{l}\text { Streptococcus } \\
\text { mutans }\end{array}$ & Prostatic abscess & $\begin{array}{l}\text { Purulent } \\
\text { abscess } \\
\text { material }\end{array}$ & $\begin{array}{l}\text { Ampicillin } \\
\text { Gentamicin } \\
\text { Ceftriaxone } \\
\text { Amoxicillin }\end{array}$ & Not described \\
\hline QU L et al., 2003 & 37-Male & $\begin{array}{l}\text { Transplantation } \\
\text { of part of the } \\
\text { intestine } \\
\text { (Crohn's disease) }\end{array}$ & $\begin{array}{l}\text { Nocardia } \\
\text { asteroides }\end{array}$ & Prostatitis & Urine & $\begin{array}{c}\text { Ciprofloxacin } \\
\text { Ampicillin-Sulbactam } \\
\text { Ceftriaxone } \\
\text { Trimethoprim- } \\
\text { Sulfamethoxazole }\end{array}$ & Not described \\
\hline $\begin{array}{l}\text { Martinaud C } \\
\text { et al., } 2008\end{array}$ & 92-Male & $\begin{array}{c}\text { Prostatic } \\
\text { adenoma } \\
\text { Arterial } \\
\text { hypertension } \\
\text { Parkinson }\end{array}$ & $\begin{array}{l}\text { Actinotignum } \\
\text { schaalii }\end{array}$ & $\begin{array}{c}\text { Sepsis } \\
\text { Prostatitis }\end{array}$ & Urine & $\begin{array}{l}\text { Ofloxacin } \\
\text { Ceftriaxone } \\
\text { Gentamicin } \\
\text { Amoxicillin }\end{array}$ & $\begin{array}{l}\text { RNAr 16S gene } \\
\text { sequencing }\end{array}$ \\
\hline $\begin{array}{l}\text { Torres E et al., } \\
2013\end{array}$ & 48-Male & $\begin{array}{l}\text { Arterial } \\
\text { hypertension } \\
\text { Left ventricular } \\
\text { hypertrophy } \\
\text { Renal failure }\end{array}$ & $\begin{array}{l}\text { Actinotignum } \\
\text { schaalii }\end{array}$ & Prostatitis & $\begin{array}{l}\text { Seminal fluid } \\
\text { Urine }\end{array}$ & $\begin{array}{l}\text { Amoxicillin- } \\
\text { clavulanic acid }\end{array}$ & $\begin{array}{c}\text { MALDI-TOF } \\
\text { RNAr 16S } \\
\text { gene sequencing }\end{array}$ \\
\hline $\begin{array}{l}\text { Siller M et al., } \\
2016\end{array}$ & 43-Male & Not described & $\begin{array}{l}\text { Actinotignum } \\
\text { schaalii }\end{array}$ & $\begin{array}{l}\text { Chronic } \\
\text { prostatitis }\end{array}$ & $\begin{array}{l}\text { Urethral } \\
\text { exudate }\end{array}$ & $\begin{array}{l}\text { Amoxicillin- } \\
\text { clavulanic acid }\end{array}$ & MALDI-TOF \\
\hline $\begin{array}{c}\text { Kawahara K } \\
\text { et al., } 2018\end{array}$ & 29-Male & Not described & $\begin{array}{c}\text { Neisseria } \\
\text { meningitidis }\end{array}$ & $\begin{array}{l}\text { Prostatitis } \\
\text { Arthritis }\end{array}$ & Urine & Not described & Not described \\
\hline
\end{tabular}

In the non-filtered search, 950 articles were initially retrieved for "urinary tract infection" and "emerging pathogens", and 12 of these met eligibility criteria for inclusion (Table 1); 699 articles were retrieved for urethritis bacteria, of which 26 were included in the review (Table 2), 580 for cervix bacteria, of which three were included; 1574 for vaginitis bacteria, of which 4 were included (Table 3); 79 for "balanitis or posthitis" bacteria, of which one was included; and 620 for "prostatitis or epididymitis" bacteria, of which six were included (Table 3).

\subsection{Study of Suspected Clinical Episodes}

From January 2016 through December 2019, 50,823 clinical episodes were microbiologically studied for suspicion of UTI, and 15,736 (30.96\%) were positive for significant bacteriuria, including $223(1.4 \%)$ produced by culturable emerging microorganisms. Among 2618 episodes with suspicion of genital infection, $1.113(42.5 \%)$ were positive, including $88(7.9 \%)$ produced by emerging microorganisms (Tables 4 and 5). Over the same period, 45 positive genitourinary episodes were recorded in 2016, 80 in 2017, 109 in 2018, and 77 in 2019. In samples from urinary episodes, the most frequent emerging microorganisms were SBG (91 episodes), followed by Gardnerella vaginalis, Aerococcus urinae, Aerococcus sanguinicola, and, in nephrology patients and patients aged $>65$ years, Lactobacillus spp.

By sex (Table S2), the most frequent emerging microorganisms in UTI episodes were SBG $(58.5 \%)$ and G. vaginalis $(23.6 \%)$ in females and Aerococcus spp. $(28.8 \%)$ and Corynebacterium spp. $(16.9 \%)$ in males $(p<0.001)$. By age (Table S3), the most frequent microorganism was SBG (88.9\%) in children (aged $\leq 14$ years), whereas there was a wider distribution of microorganisms in adults (aged > 14 years): SBG in $45.7 \%$, G. vaginalis in $23.2 \%$, Aerococcus spp. in $15.9 \%$, Lactobacillus spp. in $7.9 \%$, and Corynebacterium spp. in $7.3 \%)(p<0.016)$. By sex (Table S4), the most frequent emerging microorganisms in episodes of genital infection were G. vaginalis (35.6\%) and Corynebacterium glucuronolyticum (32.2\%) 
in males (all adults), and SVG (45.5\%) and Eikenella corrodens (27.3\%) in females (almost all adults) $(p<0.001)$.

Table 4. Presence of emerging microorganisms in the series of clinical samples.

\begin{tabular}{|c|c|c|c|c|c|c|c|}
\hline Microorganism & Urine Male & Urine Female & $\begin{array}{l}\text { Endocervical } \\
\text { Exudate }\end{array}$ & $\begin{array}{l}\text { Urethral } \\
\text { Exudate }\end{array}$ & Glans Exudate & Semen & Total \\
\hline Actinobaculum massiliensis & 2 & 1 & 1 & & & & 4 \\
\hline Actinotignum schaalii & 2 & 2 & 1 & 1 & 2 & 1 & 9 \\
\hline Actinotignum sanguinis & & & & & 1 & 1 & 2 \\
\hline Actinomyces turicensis & 4 & & 1 & & & & 5 \\
\hline Aerococcus christensenii & & & 1 & & & & 1 \\
\hline Aerococcus urinae & 11 & 7 & & & 2 & 1 & 21 \\
\hline Aerococcus sanguinicola & 6 & 4 & & & & 1 & 11 \\
\hline Aerococcus viridans & & 1 & & & & & 1 \\
\hline Aeromonas hydrophila & & & 1 & & & & 1 \\
\hline Alloscardovia omnicolens & & 1 & 1 & & & 1 & 3 \\
\hline Corynebacterium amycolatum & & 4 & & & 1 & 1 & 6 \\
\hline $\begin{array}{l}\text { Corynebacterium } \\
\text { aurimucosum }\end{array}$ & 1 & & & & & & 1 \\
\hline $\begin{array}{l}\text { Corynebacterium } \\
\text { glucuronolyticum }\end{array}$ & 5 & 1 & 1 & 5 & 1 & 12 & 25 \\
\hline Corynebacterium jeikeium & 1 & 1 & & & & & 2 \\
\hline $\begin{array}{c}\text { Corynebacterium } \\
\text { minutissimum }\end{array}$ & & 1 & & & & & 1 \\
\hline Corynebacterium striatum & 2 & & & & & & 2 \\
\hline Corynebacterium urealyticum & 5 & 1 & 1 & & & & 7 \\
\hline Eikenella corrodens & & & 3 & & & & 3 \\
\hline Facklamia hominis & 1 & 1 & 1 & 1 & 1 & 2 & 7 \\
\hline Gardnerella vaginalis & 9 & 29 & & 10 & 1 & 10 & 59 \\
\hline Lactobacillus crispatus & & 3 & & & & & 3 \\
\hline Lactobacillus delbrueckii & & 3 & & & & & 3 \\
\hline Lactobacillus fermentum & & 1 & & & & & 1 \\
\hline Lactobacillus gasserii & 4 & 6 & & & & & 10 \\
\hline Lactobacillus iners & & & & & & 1 & 1 \\
\hline Lactobacillus jensenii & & 4 & & & & & 4 \\
\hline Lactobacillus rhamnosus & 1 & 1 & & & & & 2 \\
\hline Leptotrichia trevisanii & & & 1 & & & & 1 \\
\hline Moraxella osloensis & & & 1 & 1 & & & 2 \\
\hline Neisseria meningitidis & & & 2 & & & & 2 \\
\hline Pasteurella bettyae & & & 1 & 2 & & & 3 \\
\hline Streptococcus group bovis & 19 & 72 & & & & 3 & 91 \\
\hline $\begin{array}{l}\text { Streptococcus group viridans } \\
\text { (anginosus, constellatus) }\end{array}$ & 4 & 2 & 7 & & 1 & & 14 \\
\hline Streptococcus pneumoniae & & & 1 & & & & 1 \\
\hline TOTAL & 77 & 146 & 24 & 20 & 10 & 34 & 311 \\
\hline
\end{tabular}

Urethral samples were all from male patients, and the most frequent microorganisms were $G$. vaginalis ( $n=10$ isolates) and C. glucuronolyticum $(n=5)$. In endocervical exudates $(n=24)$, the most frequent microorganism was SVG $(n=7)$. In semen and glans exudate samples, the most frequent microorganisms were $C$. glucuronolyticum $(n=13)$ and G. vaginalis $(n=11)$.

The susceptibility of the detected uropathogens is exhibited in Table 6, highlighting the resistances obtained for Corynebacterium spp., SBG, SVG and Lactobacillus spp. Among genital infections (Tables 7-9), resistance to clindamycin and metronidazole was observed for Actinobaculum massiliensis and Actinotignum schaalii and resistance to some penicillins for Neisseria meningitidis. 
Table 5. Annualized presence of emerging microorganisms in study of genital infection in males and females.

\begin{tabular}{|c|c|c|c|c|c|}
\hline Microorganism & 2016 & 2017 & 2018 & 2019 & Total \\
\hline Actinotignum schaalii & & & 3 & 2 & 5 \\
\hline Actinobaculum massiliensis & & & 1 & & 1 \\
\hline Actinotignum sanguinis & & & 1 & 1 & 2 \\
\hline Actinomyces turicensis & & 1 & & & 1 \\
\hline Aerococcus christensenii & & & 1 & & 1 \\
\hline Aerococcus urinae & & & 2 & 1 & 3 \\
\hline Aerococcus sanguinicola & & & & 1 & 1 \\
\hline Aeromonas hydrophila & 1 & & & & 1 \\
\hline Alloscardovia omnicolens & & & 1 & 1 & 2 \\
\hline C. amycolatum & & & 2 & & 2 \\
\hline C. glucuronolyticum & & & 11 & 8 & 19 \\
\hline C. urealyticum & & & 1 & & 1 \\
\hline Eikenella corrodens & & 2 & 1 & & 3 \\
\hline Facklamia hominis & & & 3 & 2 & 5 \\
\hline Gardnerella vaginalis & 2 & 2 & 7 & 10 & 21 \\
\hline Lactobacillus iners & 1 & & & & 1 \\
\hline Leptotrichia trevisanii & & 1 & & & 1 \\
\hline Moraxella osloensis & & 2 & & & 2 \\
\hline Neisseria meningitidis & 1 & 1 & & & 2 \\
\hline Pasteurella bettyae & & 1 & & 2 & 3 \\
\hline Streptococcus group bovis & 2 & 1 & & & 3 \\
\hline $\begin{array}{l}\text { Streptococcus group viridans } \\
\text { (anginosus, constellatus) }\end{array}$ & 1 & 2 & 1 & 4 & 8 \\
\hline S. pneumoniae & & & 1 & & 1 \\
\hline Total & 8 & 13 & 35 & 32 & 89 \\
\hline
\end{tabular}

Table 6. Percentage antibiotic susceptibility of emerging microorganisms isolated in UTI *.

\begin{tabular}{|c|c|c|c|c|c|c|c|c|c|c|c|}
\hline \multicolumn{2}{|c|}{ Agent } & \multicolumn{10}{|c|}{ Susceptibility (\%) } \\
\hline & & $\begin{array}{c}\text { A. massili- } \\
\text { ensis } \\
(n=3)\end{array}$ & $\begin{array}{c}\text { A. } \\
\text { schaalii } \\
(n=4)\end{array}$ & $\begin{array}{l}\text { A. urinae } \\
(n=18)\end{array}$ & $\begin{array}{c}\text { A. san- } \\
\text { guinicola } \\
(n=10)\end{array}$ & $\begin{array}{c}\text { A. } \\
\text { viridans } \\
(n=1)\end{array}$ & $\begin{array}{l}\text { Corynebacterium } \\
\quad(n=22)\end{array}$ & $\begin{array}{l}\text { F. hominis } \\
(n=2)\end{array}$ & $\begin{array}{c}\text { Lactobaci- } \\
\text { llus }^{* *} \\
(n=23)\end{array}$ & $\begin{array}{l}S . \text { group } \\
\text { bovis } \\
(n=91)\end{array}$ & $\begin{array}{c}\text { S. group } \\
\text { viridans } \\
(n=6)\end{array}$ \\
\hline \multirow{4}{*}{ Pen } & $\mathrm{P}$ & 100 & 100 & 90 & 100 & 0 & 8 & & 100 & 90 & 33 \\
\hline & AMP & & 100 & 100 & 100 & & & 0 & 70 & 100 & 50 \\
\hline & AMC & 100 & & & & & & & 100 & & \\
\hline & $\mathrm{TZP}$ & 100 & & & & & & & & & \\
\hline \multirow{2}{*}{ Cef } & CTX & & 100 & 100 & 100 & 100 & 14 & 100 & & & 100 \\
\hline & CFM & & & & & & 0 & & & & \\
\hline \multirow[b]{2}{*}{ Carba } & IPM & 100 & 100 & & & & 0 & & 70 & & \\
\hline & MEM & 100 & & 90 & 100 & & 29 & & 100 & & 100 \\
\hline \multirow{3}{*}{ Quino } & $\mathrm{CIP}$ & & & 88 & 22 & 100 & 27 & & & & \\
\hline & LEV & & 0 & & & & 0 & 100 & 0 & 77 & 50 \\
\hline & MXF & 33 & 100 & & & & & & & & \\
\hline Amg & $\mathrm{CN}$ & & & 0 & & & 69 & & & & \\
\hline Gcp & VA & 100 & 100 & 100 & 100 & & & & & 100 & 100 \\
\hline Tetra & $\mathrm{TE}$ & & 100 & 100 & & & 92 & & & 21 & 100 \\
\hline Ntm & MTZ & 0 & 0 & & & & & & 0 & & \\
\hline Rif & $\mathrm{RD}$ & & & 100 & 100 & & 100 & & & & \\
\hline \multirow{3}{*}{ Various } & SXT & & & 0 & 0 & & & & & & \\
\hline & FOS & & & & & & 0 & & 0 & 99 & \\
\hline & $\mathrm{F}$ & & & 100 & 100 & & & & & 100 & \\
\hline
\end{tabular}

* Antibiogram not performed for A. turicensis $(n=4)$, A. omnicolens $(n=1)$, or G. vaginalis $(n=38)$. ${ }^{* *}$ Lactobacillus: crispatus, delbrueckii, fermentum, gasseri, jensenii, rhamnosus. Penicillins (Pen), Cephalosporins (Cef), Carbapenems (Carba), Quinolones (Quino), Aminoglycosides (Amg), Glycopeptides (Gcp), Tetracycline (Tetra), Nitroimidazole (Ntm), Rifampicin (Rif), Sulfamides (Sulf), Amoxicillin-Clavulanic (AMC), Ampicillin (AMP), Penicillin (P), Piperacillin-Tazobactam (TZP), Cefotaxime (CTX), Cefixime (CFM), Imipenem (IPM), Meropenem (MEM), Ciprofloxacin (CIP), Levofloxacin (LEV), Moxifloxacin (MXF), Gentamicin (CN), Teicoplanin (TEC), Vancomycin (VA), Tetracycline (TE), Metronidazole (MTZ), Rifampicin (RD), Trimethoprim-Sulfamethoxazole (SXT), Fosfomycin (FOS), Nitrofurantoin (F). 
Table 7. Percentage antibiotic susceptibility of emerging microorganisms isolated in urethral exudate *

\begin{tabular}{|c|c|c|c|c|c|c|}
\hline \multicolumn{2}{|c|}{ Agents } & \multicolumn{5}{|c|}{ Susceptibility (\%) } \\
\hline & & $\begin{array}{c}\text { A. schaalii } \\
(n=1)\end{array}$ & $\begin{array}{c}\text { C. glucuronolyticum } \\
(n=5)\end{array}$ & $\begin{array}{l}\text { F. hominis } \\
(n=1)\end{array}$ & $\begin{array}{l}\text { M. osloensis } \\
(n=1)\end{array}$ & $\begin{array}{c}\text { P. bettyae } \\
(n=2)\end{array}$ \\
\hline \multirow{3}{*}{ Pen } & $\mathrm{P}$ & & 20 & 100 & & 100 \\
\hline & $\mathrm{AMP}$ & 100 & & & 100 & 100 \\
\hline & AMC & & & 100 & 100 & 100 \\
\hline Cef & CTX & & 40 & & 100 & \\
\hline \multirow{2}{*}{ Carba } & IMP & & & 100 & & \\
\hline & MEM & & 0 & & 100 & \\
\hline \multirow{3}{*}{ Quino } & $\mathrm{CIP}$ & & 40 & & & 100 \\
\hline & LEV & & & & 100 & \\
\hline & MXF & & & 100 & & \\
\hline Amg & $\mathrm{CN}$ & & 60 & & & \\
\hline Gcp & VA & 100 & 100 & 100 & & \\
\hline \multirow{2}{*}{ Tetra } & TE & 100 & 60 & & & \\
\hline & $\mathrm{DO}$ & & & & & 100 \\
\hline \multirow{2}{*}{ Mcr } & $\mathrm{E}$ & & 0 & & & \\
\hline & AZM & & & & 100 & \\
\hline Linco & $\mathrm{DA}$ & 100 & 0 & 0 & & \\
\hline Oxa & LZD & & 100 & & & \\
\hline Ntm & MTZ & 0 & & 0 & & \\
\hline Rif & $\mathrm{RD}$ & & 100 & & & \\
\hline Sulf & SXT & & 100 & & 100 & 100 \\
\hline
\end{tabular}

* Antibiogram was not performed for G. vaginalis $(n=10)$. Penicillins (Pen), Cephalosporins (Cef), Carbapenems (Carba), Quinolones (Quino), Aminoglycosides (Amg), Glycopeptides (Gcp), Tetracycline (Tetra), Macrolides (Mcr), Lincosamides (Linco), Oxazolidone (Oxa), Nitroimidazole (Ntm), Rifampicin (Rif), Sulfamides (Sulf), AmoxicillinClavulanic (AMC), Ampicillin (AMP), Penicillin (P), Piperacillin-Tazobactam (TZP), Cefotaxime (CTX), Imipenem (IPM), Meropenem (MEM), Ciprofloxacin (CIP), Levofloxacin (LEV), Moxifloxacin (MXF), Gentamicin (CN), Vancomycin (VA), Tetracycline (TE), Doxycycline (DO), Erythromycin (E), Azithromycin (AZM), Clindamycin (DA), Linezolid (LZD), Metronidazole (MTZ), Rifampicin (RD), Trimethoprim-Sulfamethoxazole (SXT).

Table 8. Percentage antibiotic susceptibility of emerging microorganisms isolated in genital samples from females *.

\begin{tabular}{|c|c|c|c|c|c|c|c|c|c|c|c|c|c|}
\hline \multicolumn{2}{|c|}{ Agent } & \multicolumn{12}{|c|}{ Susceptibility (\%) } \\
\hline & & $\begin{array}{c}\text { A. } \\
\text { massilien- } \\
\text { sis } \\
(n=1)\end{array}$ & $\begin{array}{c}\text { A. } \\
\text { schaa- } \\
\text { lii } \\
(n=1)\end{array}$ & $\begin{array}{c}\text { A. } \\
\text { hydrophi- } \\
\text { la } \\
(n=1)\end{array}$ & $\begin{array}{c}\text { A. } \\
\text { omnico- } \\
\text { lens } \\
(n=1)\end{array}$ & $\begin{array}{l}\text { Corynebacte- } \\
\text { rium } \\
(n=2)\end{array}$ & $\begin{array}{c}\text { E. corro- } \\
\text { dens } \\
(n=3)\end{array}$ & $\begin{array}{c}L . \\
\text { trevisa- } \\
n i i \\
(n=1)\end{array}$ & $\begin{array}{c}\text { M. } \\
\text { osloen- } \\
\text { sis } \\
(n=1)\end{array}$ & $\begin{array}{c}N . \\
\text { meningiti- } \\
\text { dis } \\
(n=2)\end{array}$ & $\begin{array}{c}P . \\
\text { bettyae } \\
(n=1)\end{array}$ & $\begin{array}{c}S . \\
\text { pneumo- } \\
\text { niae } \\
(n=1)\end{array}$ & $\begin{array}{c}S . \\
\text { group } \\
\text { viri- } \\
\text { dans } \\
(n=7)\end{array}$ \\
\hline \multirow{3}{*}{ Pen } & $\begin{array}{c}\mathrm{P} \\
\mathrm{PP}\end{array}$ & 100 & & & & & & 100 & & 0 & & 100 & 86 \\
\hline & AMP & & & 0 & 100 & & 100 & & 100 & 0 & 100 & & \\
\hline & $\begin{array}{l}\text { AMC } \\
\text { TZP }\end{array}$ & 100 & 100 & $\begin{array}{c}0 \\
100\end{array}$ & & 100 & 100 & 100 & 100 & & 100 & 100 & \\
\hline \multirow{7}{*}{ Cef } & KZ & & & 0 & & & & & & & & & \\
\hline & FOX & & & 100 & & & & & & & & & \\
\hline & CXM & & & 100 & & & & & & & & & \\
\hline & CTX & & & 100 & & & 100 & & 100 & 100 & & 100 & 83 \\
\hline & CFM & & & & & & & & & & & & \\
\hline & CAZ & & & 100 & & & & & & & & & \\
\hline & FEP & & & 100 & & & & & & & & & \\
\hline \multirow{3}{*}{ Carb } & ETP & & & 100 & & & & & & & & & \\
\hline & IMP & 100 & & 100 & & & 100 & 100 & & & & & 100 \\
\hline & MEM & & & & & & & & 100 & 100 & & 100 & 100 \\
\hline Mbac & ATM & & & 100 & & & & & & & & & \\
\hline
\end{tabular}


Table 8. Cont.

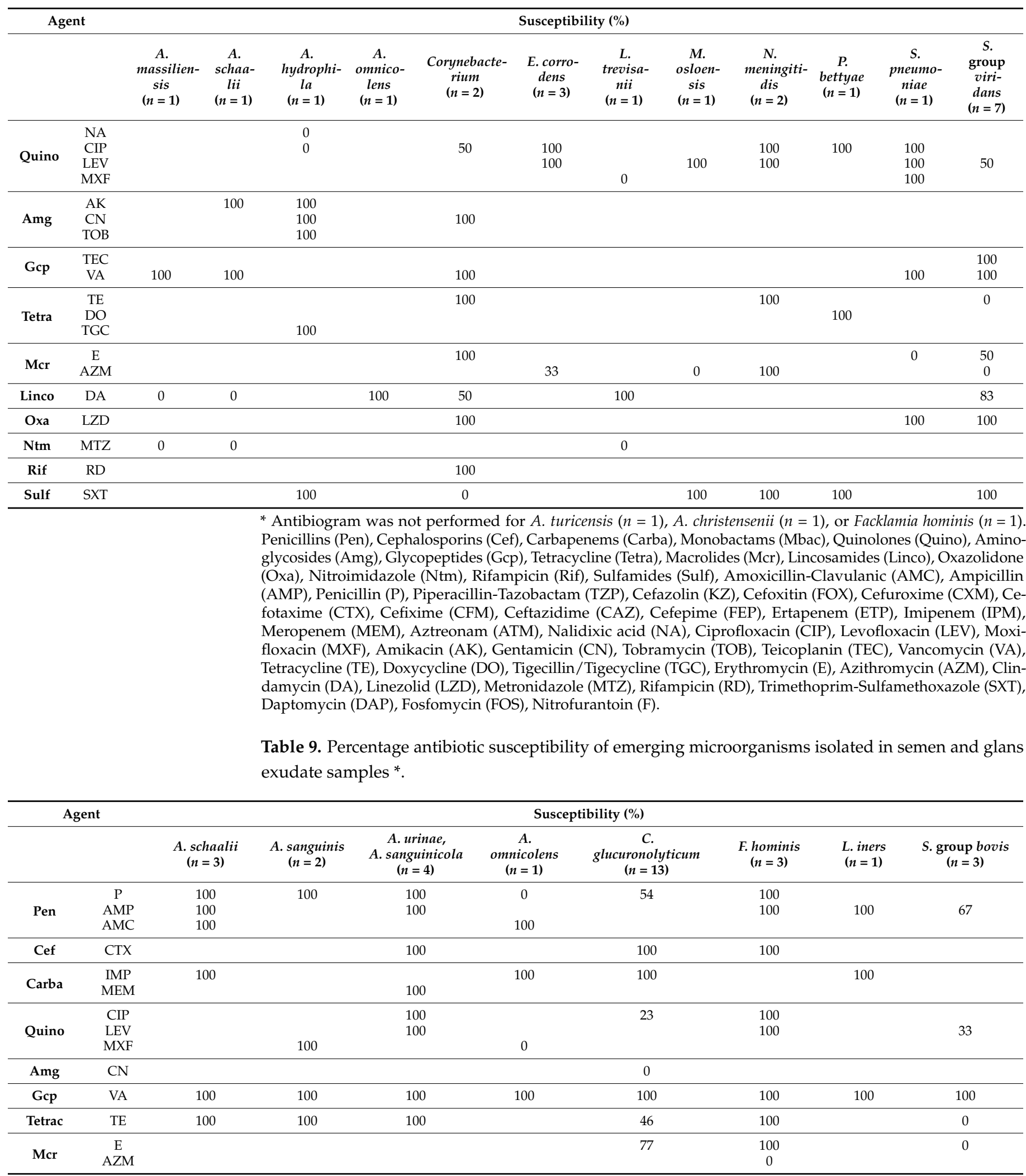


Table 9. Cont.

\begin{tabular}{|c|c|c|c|c|c|c|c|c|c|}
\hline \multicolumn{2}{|c|}{ Agent } & \multicolumn{8}{|c|}{ Susceptibility (\%) } \\
\hline & & $\begin{array}{l}\text { A. schaalii } \\
\quad(n=3)\end{array}$ & $\begin{array}{l}\text { A. sanguinis } \\
(n=2)\end{array}$ & $\begin{array}{c}\text { A. urinae, } \\
\text { A. sanguinicola } \\
(n=4)\end{array}$ & $\begin{array}{c}A . \\
\text { omnicolens } \\
(n=1)\end{array}$ & $\begin{array}{c}C . \\
\substack{\text { glucuronolyticum } \\
(n=13)}\end{array}$ & $\begin{array}{l}\text { F. hominis } \\
\quad(n=3)\end{array}$ & $\begin{array}{l}\text { L. iners } \\
(n=1)\end{array}$ & $\begin{array}{l}\text { S. group bovis } \\
\quad(n=3)\end{array}$ \\
\hline Linco & $\mathrm{DA}$ & 100 & & & 100 & 23 & & & 67 \\
\hline Oxa & LZD & & & & 100 & & 100 & & 100 \\
\hline Ntm & MTZ & 0 & 0 & & 0 & & & & \\
\hline Rif & $\mathrm{RD}$ & & & 100 & & 100 & & & \\
\hline \multirow[t]{4}{*}{ Sulf } & SXT & 0 & & & & 100 & & & \\
\hline & FOS & & & & & 0 & & & 100 \\
\hline & $\mathrm{F}$ & & & 100 & & & & & \\
\hline & & & $\begin{array}{l}{ }^{*} \text { Antibiogram } \\
(n=1) . \text { Penic } \\
\text { (Amg), Glyco } \\
\text { Nitroimidazo } \\
\text { cillin (P), Cefc } \\
\text { ifloxacin (MX } \\
\text { Clindamycin } \\
\text { (SXT), Daptor }\end{array}$ & $\begin{array}{l}\text { was not perform } \\
\text { lins (Pen), Ceph } \\
\text { eeptides (Gcp), T } \\
\text { (Ntm), Rifampi } \\
\text { taxime (CTX), Im } \\
\text { ), Gentamicin (C } \\
\text { DA), Linezolid ( } \\
\text { tycin (DAP), Fos }\end{array}$ & $\begin{array}{l}\text { d for C. amyc } \\
\text { losporins (C } \\
\text { tracycline (T } \\
\text { n (Rif), Sulfar } \\
\text { benem (IPM), } \\
\text { J), Vancomyc } \\
\text { ZD), Metron } \\
\text { mycin (FOS) }\end{array}$ & $\begin{array}{l}\text { tum }(n=2), \text { G. vag } \\
\text { Carbapenems (C } \\
\text { a), Macrolides (M } \\
\text { des (Sulf), Amoxici } \\
\text { leropenem (MEM) } \\
\text { (VA), Tetracycline } \\
\text { azole (MTZ), Rifar } \\
\text { Jitrofurantoin (F). }\end{array}$ & $\begin{array}{l}\text { is }(n=11), c \\
\text { a), Quinolo } \\
\text { Lincosami } \\
\text {-Clavulanic } \\
\text { profloxacin } \\
\text { E), Erythron } \\
\text { icin (RD), T }\end{array}$ & $\begin{array}{l}\text { viridans } \\
\text { (Quino) } \\
\text { (Linco), } \\
\text { MC), Am! } \\
\text { P), Levof } \\
\text { in (E), Az } \\
\text { ethoprim }\end{array}$ & $\begin{array}{l}\text { up (S. anginosus) } \\
\text { minoglycosides } \\
\text { azolidone (Oxa), } \\
\text { llin (AMP), Peni- } \\
\text { acin (LEV), Mox- } \\
\text { romycin (AZM), } \\
\text { llfamethoxazole }\end{array}$ \\
\hline
\end{tabular}

\section{Discussion}

Bacterial infections of the genitourinary tract are frequently empirically treated with generic antibiotics because routine laboratory procedures are unable to provide a diagnosis. However, advances in the diagnostic procedures available to clinical microbiology laboratories (e.g., mass spectrometry-MALDI-TOF, media enrichment and molecular techniques) have improved identification of the microorganisms responsible for these infections, allowing specifically targeted treatments to be applied in a larger proportion of cases [8].

Overall, the findings of the systematic review of 54 selected studies are comparable with the results obtained in the laboratory of our hospital. They indicate that microorganisms responsible for genital infection can sometimes be opportunistic and may or may not be usually present in the genital tract. For instance, they can be introduced into the genital tract during sexual activity without barrier protection or from intrauterine devices, tampons, and exploratory medical procedures, among others, and pregnancy and previous disease may also play a role. Hence, understanding of the development of disease by emerging microorganisms is hampered by the influence of numerous and heterogeneous predisposing factors [9]. The evidence presented here (Tables 2 and 3) confirms the implication of these microorganisms in episodes of genital infection. In line with findings published in the reviewed articles, the microorganisms most frequently detected among males in the present series were N. meningitidis, Corynebacterium spp., streptococci and, finally, G. vaginalis. It has been reported that $G$. vaginalis forms part of the urogenital microbiota in $7-11 \%$ of males and may represent a focus of infection [10,11]. Likewise, the predominant microorganisms in females were S. anginosus and S. constellatus, which form part of the oral, respiratory, and gastrointestinal microbiota but can produce clinical infections when outside their usual habitat [12]. The low percentage susceptibility of these infections to penicillin and levofloxacin, frequently associated with resistance to macrolides, cotrimoxazole, tetracyclines, streptogramin B, or lincosamides [13], hinders their treatment. Three isolates of E. corrodens were detected in samples from females; this microorganism is part of the oral microbiota but can produce gynecological infections, frequently polymicrobial, including pelvic inflammatory disease in IUD carriers and chorioamnionitis [14]. In contrast, genus Pasteurella spp. is infrequent in genital samples and its detection is therefore of particular interest [15]. Facklamia hominis is also a highly infrequent pathogen in humans, although its prevalence may be underestimated, and it was detected in samples from episodes of UTI, urethritis, and balanoposthitis in the present study. The variability of its susceptibility profile complicates the management of infection with this microorganism, and there is no established empirical treatment $[16,17]$, so that antibiotic susceptibility 
studies are necessary. In the present series, isolates of Moraxella osloensis were detected in samples from episodes of urethritis and genital infection. This microorganism is susceptible to most of the studied antibiotics except for azithromycin, although the most appropriate therapy is not well established [18-20]. The isolate of Alloscardovia omnicolens detected was not susceptible to metronidazole or moxifloxacin, as previously reported [21,22]. Leptotrichia can be part of the oral microbiota, and immunosuppression or vaginal mucosal erosion can be predisposing factors for disease after translocation, and it is usually resistant to moxifloxacin $[23,24]$. Finally, N. meningitidis has been isolated in the ge-nital tract as a cause of urethritis and is commonly susceptible to most studied antibiotics, including amoxicillin, ceftriaxone, and doxycycline [25], although resistance to penicillin and ampicillin was observed in the present study.

In relation to UTI, both the reviewed articles and the present study describe the frequent presence of Corynebacterium spp., Aerococcus spp. and Actinotignum spp. which have been considered contaminants, possibly favoring their underdiagnosis. Moreover, some of these have phenotypic characteristics similar to those of enterococci or streptococci, as in the case of Aerococcus spp., leading to frequent confusion. A further cause of the underestimation of Corynebacterium spp. as a UTI producer may have been the absence of enriched media to achieve their growth [5], given that they usually grow slowly with minuscule colonies on blood agar medium in the presence of $\mathrm{CO}_{2}$. In the present series, blood agar culture medium was used for at-risk populations, including nephrology patients and those of an advanced age, facilitating the detection of emerging microorganisms. Emerging uropathogens include the SBG, especially Streptococcus gallolyticus, subspecies pasteurianus, although species and subspecies could not be specified in all cases and these data are therefore not reported; however, studies using MALDI-TOF have shown that almost all SBG isolates correspond to the aforementioned subspecies [26]. Most episodes with SBG isolates were in adult women, in line with a previous report that $S$. gallolyticus is a potential agent responsible for bacteriuria in females with a history of urological disease and/or diabetes [12]. The ability to select the appropriate therapy is limited by the lack of clinical cutoff points to interpret antibiograms, which have only been established for ampicillin, penicillin, vancomycin, teicoplanin, and clindamycin. Epidemiological cutoff points are frequently used to overcome this limitation, and in general there have been reports of resistance to erythromycin, clindamycin, levofloxacin, and cotrimoxazole, especially for S. gallolyticus [27]. G. vaginalis is currently considered a possible uropathogen with likely sexual transmission to males, explaining its increased detection in male urine cultures and genital disease, although it continues to be underdiagnosed [11]. It was detected in urine samples from nephrology patients thanks to the utilization of blood agar medium (see above). Another relevant genus is Aerococcus spp., highlighting the predominance of $A$. urinae and $A$. sanguinicola in elderly males with underlying urological disease, who are at higher risk of UTI from infrequent pathogens [28]. Nevertheless, its possible presence should also be considered in adolescents because the diagnosis is often delayed and potentially severe disease (e.g., pyelonephritis, bacteremia, endocarditis or peritonitis) can develop [29]. It is therefore important to rule out the genus Aerococcus genus when a urine culture has a significant alpha-hemolytic microorganism count before reporting it as urogenital microbiota. Antibiotic susceptibility cutoff points for Aerococcus spp. were published by EUCAST in 2017 [30] and by CLSI in 2015 [31]. This genus is usually susceptible to beta-lactams, the antibiotic of choice, and to vancomycin, which is reserved for allergic patients in combination with gentamycin [32]. However, A. viridans has elevated minimum inhibitory concentration (MIC) values for penicillin and aminoglycosides, and resistance to vancomycin has been reported $[33,34]$. Both the review and our laboratory results evidence elevated MICs for nitrofurantoin, fluoroquinolones, and cotrimoxazole [28]. The susceptibility varies among species, and a susceptibility study is necessary before the selection of antibiotic. Lactobacillus gasserii and Lactobacillus delbueckii were frequently detected in our urine samples, especially in women of advanced age. Both, especially the former, are considered contaminant microbiota as part of the normal vaginal, gastrointestinal, and 
oropharyngeal microbiota that can translocate to the urinary system. They have a low virulence, except in patients with immunosuppression or mucosal erosion or undergoing endoscopic procedures [35]. There are documented cases of endocarditis, chorioamnionitis, and renal abscesses in patients with underlying kidney disease, and this possibility should be considered by clinicians [36,37]. All emerging microorganisms under study were mainly detected in adults, and their isolation in samples from children has been exceptional. In fact, the only frequent microorganism observed in the children was SBG, with 16 episodes.

In our laboratory, Corynebacterium spp. and Actinotignum spp. were frequently present in urine cultures and genital exudates, highlighting the presence of C. urealyticum and C. glucuronolyticum, which was especially prevalent among males. Most species of this genus are mucoepithelial microbiota, which can be opportunistic pathogens of the genitourinary system. In cases of suspected infection by Corynebacterium spp., incubation should be prolonged when the culture remains negative at $24 \mathrm{~h}$ given their slow growth [38], or blood agar media should be used. Corynebacterium spp. have undergone the largest number of susceptibility studies because of an increase in the resistance of this genus over recent years. The data from our hospital reveal resistance to penicillin and gentamycin and a high degree of resistance to ciprofloxacin, tetracyclines and lincosamides, limiting the usefulness of these antibiotics [38-40]. A. schaalii and A. sanguinis species of the genus Actinotignum were isolated in the present series, and $A$. schaalii was frequently associated with UTI. The presence of this genus may be underdiagnosed because the identification is technically challenging and a prolonged culture time is required, with the need to apply molecular techniques in some cases. Its presence has been related to humidity in the ge-nital area due to diaper use or incontinence, among other causes [41]. Actinotignum is commonly resistant to fluoroquinolones and cotrimoxazole, and empirical treatment with beta-lactams is recommended [42]. The most prevalent species in the present study was A. schaalii, which is resistant to metronidazole, clindamycin and, occasionally, to nitrofurantoin and gentamicin. It is susceptible to beta-lactams (except for mecillinam), tetracyclines, vancomycin, rifampicin, and linezolid [43,44]. Actinobacullum massiliensis is phylogenetically close to Actinotignum spp. and may be part of the genitourinary tract microbiota, but it is also a potential pathogen [45].

This is an observational single-center study with no control group. A further potential limitation is that isolates might have translocated from habitats in which they form part of the microbiota (in which case they are of clinical interest) or they might have been part of the microbiota at the site of their detection. However, the presence of isolates was only reported when detected in a non-habitual localization in order to strengthen the scientific rigor of the study. In addition, strict microbiological criteria were applied, including only those with monomicrobial presence and a significant count in urine cultures or an abundant presence in genital exudates. Habitual pathogens were excluded. Special consideration was also given to samples from nephrology and elderly patients.

Although the data presented here may suggest a change in the bacterial flora causing genitourinary infections, this possibility is not supported by the present study because cultures were not followed over time. It should also be noted that exclusion of the most prevalent causes of infection [46,47] creates an incorrect picture of changes in the flora responsible for genitourinary infections. Nevertheless, further clinical research is needed to evaluate responses to the antibiotic treatments.

\section{Conclusions}

Emerging microorganisms are responsible for a small but clinically relevant proportion of genitourinary infections and are frequently resistant to antibiotics empirically prescribed to treat genitourinary infections, such as ciprofloxacin and fosfomycin. It is essential to consider them among possible genitourinary pathogens and to create an antibiogram when required. 
Supplementary Materials: The following supporting information can be downloaded at: https: / / www.mdpi.com/article/10.3390/jcm11051348/s1, Table S1: Articles in the systematic review of emerging microorganisms in the genitourinary system, Table S2: Most frequent emerging microorganisms in cases of suspected urinary infection by sex, Table S3: Most frequent emerging microorganisms in cases of suspected urinary infection by age, Table S4: Most frequent emerging microorganisms in genital samples by sex.

Author Contributions: Conceptualization, J.G.-F.; Investigation, A.R.-C., G.J.-G., L.R.-G., M.E.-R., J.M.N.-M. and J.G.-F.; Writing-original draft, J.G.-F.; Writing-review \& editing, J.M.N.-M. All authors have read and agreed to the published version of the manuscript.

Funding: This research did not receive any specific grant from funding agencies in the public, commercial, or non-profit sectors.

Institutional Review Board Statement: The study protocol complied with the principles of the Helsinki Declaration and ethical epidemiological research. No additional sampling was conducted by the laboratory, and the routine diagnostic protocol was always followed. In this non-interventionist study, biological material was only used for the standard diagnosis of urogenital tract infections as ordered by attending physicians, with no change in routine procedures. For this reason, there was no need to obtain the informed consent of patients for global results analysis, in accordance with the ethical guidelines of the World Health Organization for health-related research in humans. The database was fully anonymized, and patient episodes were only identified by their regional health record number and were replaced by any infectious episode that occurred more than 6 weeks later. Permission to access and analyze the data was granted by the Clinical Microbiology Department Management Unit. The study was approved by the Ethics and Human Research Committee of the hospital (code \#0751-N-20).

Informed Consent Statement: Not applicable.

Data Availability Statement: The data presented in this study are available in the main text.

Conflicts of Interest: The authors declare no conflict of interest.

\section{References}

1. Abercrombie, G.F.; Allen, J.; Maskell, R. Cornyebacterium vaginale urinary-tract infection in a man. Lancet 1978, 1, 766. [CrossRef]

2. Ronald, A. The etiology of urinary tract infection: Traditional and emerging pathogens. Am. J. Med. 2002, 113 (Suppl. 1), 14S-19S. [CrossRef]

3. Nguyen, C.; Dascal, A.; Mendelson, J. Prostatic abscess caused by Streptococcus mutans. Can. J. Infect. Dis. 1990, 1, 82-84. [CrossRef] [PubMed]

4. Ortí, T.; Martín, A.; Palafox, E.; Bonilla, I. Urinary infection by Corynebacterium species: Presentation of 8 cases. Med. Clin. 1985, 85, 266-268.

5. Kline, K.A.; Lewis, A.L. Gram-positive uropathogens, polymicrobial urinary tract infection, and the emerging microbiota of the urinary tract. Microbiol. Spectr. 2016, 4, 4. [CrossRef]

6. EUCAST: European Commitee on Antimicrobila Susceptibility Testing. 2020. Available online: https://eucast.org/ (accessed on 30 November 2021).

7. Woods, G.L.; Brown-Elliott, B.A.; Conville, P.S.; Desmond, E.P.; Hall, G.S.; Lin, G.; Pfyffer, G.E.; Ridderhof, J.C.; Siddiqi, S.H.; Wallace, R.J., Jr.; et al. CLSI Guideline. 2020. Available online: https:/ / clsi.org/ (accessed on 30 November 2021).

8. Wolf, E.A.; Rettig, H.C.; Lupatsii, M.; Schlüter, B.; Schäfer, K.; Friedrich, D.; Graspeuntner, S.; Rupp, J. Culturomics Approaches Expand the Diagnostic Accuracy for Sexually Transmitted Infections. Int. J. Mol. Sci. 2021, 22, 10815. [CrossRef] [PubMed]

9. Beigi, R.H.; Wiesenfeld, H.C. Pelvic inflammatory disease: New diagnostic criteria and treatment. Obstet. Gynecol. Clin. N. Am. 2003, 30, 777-793. [CrossRef]

10. Lagacé-Wiens, P.R.S.; Ng, B.; Reimer, A.; Burdz, T.; Wiebe, D.; Bernard, K. Gardnerella vaginalis bacteremia in a previously healthy man: Case report and characterization of the isolate. J. Clin. Microbiol. 2008, 46, 804-806. [CrossRef]

11. Ruiz-Gómez, M.L.; Martín-Way, D.A.; Pérez-Ramírez, M.D.; Gutiérrez-Fernández, J. Male deep infections by Gardnerella vaginalis. A literature review and a case report. Rev. Esp. Quimioter. 2019, 32, 469-472.

12. Hoen, B. Infections Due to Streptococcus Bovis/Streptococcus Equinus Complex (SBSEC; Formerly Group D Streptococci); Post, T.W., Ed.; UpToDate: Waltham, MA, USA, 2021.

13. Wo, S.; Dubrovskaya, Y.; Siegfried, J.; Papadopoulos, J.; Jen, S.P. Clinical outcomes of ceftriaxone vs penicillin g for complicated viridans group streptococci bacteremia. Open Forum Infect. Dis. 2020, 8, 542. [CrossRef]

14. Correa Martínez, L.; González Velasco, C.; Gaona Álvarez, C.E.; Sánchez Castañón, J. Tuboovarian abscess due to Eikenella corrodens. Enferm. Infecc. Microbiol. Clin. 2018, 36, 319-320. [CrossRef] [PubMed] 
15. Zaramella, P.; Zamorani, E.; Freato, F.; Cattai, M.; Meloni, G.A. Neonatal meningitis due to a vertical transmission of Pasteurella multocida. Pediatr. Int. 1999, 41, 307-310. [CrossRef] [PubMed]

16. Goméz-Luque, J.M.; Foronda-García-Hidalgo, C.; Gutiérrez-Fernández, J. Balanoposthitis by Facklamia hominis in pediatrics. Rev. Esp. Quimioter. 2019, 32, 278-280. [PubMed]

17. Gahl, M.; Stöckli, T.; Fahrner, R. Facklamia hominis bacteremia after transurethral resection of the prostate: A case report. BMC Urol. 2020, 20, 192. [CrossRef]

18. Gómez-Camarasa, C.; Fernández-Parra, J.; Navarro-Marí, J.M.; Gutiérrez-Fernández, J. Moraxella osloensis emerging infection Visiting to genital infection. Rev. Esp. Quimioter. 2018, 31, 178-181.

19. Abdolrasouli, A.; Amin, A.; Baharsefat, M.; Roushan, A.; Hemmati, Y. Moraxella catarrhalis associated with acute urethritis imitating gonorrhoea acquired by oral-genital contact. Int. J. STD AIDS 2007, 18, 579-580. [CrossRef]

20. Takahashi, S.; Murata, K.; Ozawa, K.; Yamada, H.; Kawakami, H.; Nakayama, A.; Asano, Y.; Mochizuki, K.; Mikamo, H. Moraxella species: Infectious microbes identified by use of time-of-flight mass spectrometry. Jpn. J. Ophthalmol. 2019, 63, 328-336. [CrossRef]

21. Isnard, C.; Lienhard, R.; Reissier, S.; Rodriguez, S.; Krähenbühl, J.; Liassine, N.; Guérin, F.; Cattoir, V.; Information, P.E.K.F.C In vitro antimicrobial susceptibility of Alloscardovia omnicolens and molecular mechanisms of acquired resistance. Diagn. Microbiol. Infect. Dis. 2016, 84, 227-229. [CrossRef]

22. Cardona-Benavides, I.; Puertas-Prieto, A.; Pinilla-Martín, F.J.; Navarro-Marí, J.M.; Gutiérrez-Fernández, J. Alloscardovia omnicolens emerging presence in premature rupture of membranes. New Microbiol. 2019, 42, 237-239. [PubMed]

23. Eribe, E.R.K.; Olsen, I. Leptotrichia species in human infections II. J. Oral Microbiol. 2017, 9, 1368848. [CrossRef]

24. Mora-Palma, J.C.; Rodríguez-Oliver, A.J.; Navarro-Marí, J.M.; Gutiérrez-Fernández, J. Emergent genital infection by Leptotrichia trevisanii. Infection 2019, 47, 111-114. [CrossRef] [PubMed]

25. Kanemitsu, N.; Hayashi, I.; Satoh, N.; Hayakawa, T.; Mitsuya, H.; Hayase, Y.; Hiramoto, K.; Kojima, M. Acute urethritis caused by Neisseria meningitidis. Int. J. Urol. 2003, 10, 346-347. [CrossRef] [PubMed]

26. Hou-Pérez, E.; Aparicio-Gómez, J.A.; Gómez-Camarasa, C.; Gutiérrez-Fernández, J. A study of urinary tract infections by Streptococcus gallolyticus ssp. pasteurianus. Rev. Esp. Quimioter. 2019, 32, 189-191.

27. Pompilio, A.; Di Bonaventura, G.; Gherardi, G. An overview on Streptococcus bovis/Streptococcus equinus complex isolates: Identification to the species/subspecies level and antibiotic resistance. Int. J. Mol. Sci. 2019, 20, 480. [CrossRef]

28. Jiménez-Guerra, G.; Lara-Oya, A.; Martínez-Egea, I.; Navarro-Marí, J.M.; Gutiérrez-Fernández, J. Urinary tract infection by Aerococcus sanguinicola. An emerging opportunistic pathogen. Rev. Clin. Esp. 2018, 218, 351-355. [CrossRef]

29. Gutiérrez-Fernández, J.; Gámiz-Gámiz, A.; Navarro-Marí, J.M.; Santos-Pérez, J.L. Genitourinary tract infection in children due to Aerococcus other than Aerococcus viridans. Literature review and 3 case reports. Enferm. Infecc. Microbiol. Clin. 2021, 39, 156-158. [CrossRef]

30. Archive of EUCAST Tables and Documents. Available online: https://www.eucast.org/ast_of_bacteria/previous_versions_of_ documents / (accessed on 30 November 2021).

31. CLSI. Methods for Antimicrobial Dilution and Disk Susceptibility Testing of Infrequently Isolated or Fastidious Bacteria, 3rd ed.; CLSI guideline M45; Clinical and Laboratory Standards Institute: Wayne, PA, USA, 2015.

32. Carkaci, D.; Nielsen, X.C.; Fuursted, K.; Skov, R.; Skovgaard, O.; Trallero, E.P.; Lienhard, R.; Åhman, J.; Matuschek, E.; Kahlmeter G.; et al. Aerococcus urinae and Aerococcus sanguinicola: Susceptibility Testing of 120 Isolates to Six Antimicrobial Agents Using Disk Diffusion (EUCAST), Etest, and Broth Microdilution Techniques. Open Microbiol. J. 2017, 11, 160-166. [CrossRef]

33. Tai, D.B.G.; Go, J.R.; Fida, M.; Saleh, O.A. Management, and treatment of Aerococcus bacteremia and endocarditis. Int. J. Infect. Dis. 2021, 102, 584-589. [CrossRef]

34. Rasmussen, M. Aerococci and aerococcal infections. J. Infect. 2013, 66, 467-474. [CrossRef]

35. Darbro, B.W.; Petroelje, B.K.; Doern, G.V. Lactobacillus delbrueckii as the cause of urinary tract infection. J. Clin. Microbiol. 2009, 47, 275-277. [CrossRef]

36. Jiménez-Guerra, G.; Pérez-Ramírez, M.D.; Navarro-Marí, J.M.; Gutiérrez-Fernández, J. Urinary tract infection caused by Lactobacillus delbrueckii, a microorganism used as a probiotic. Rev. Esp. Quimioter. 2017, 30, 229-230.

37. Sirichoat, A.; Flórez, A.B.; Vázquez, L.; Buppasiri, P.; Panya, M.; Lulitanond, V.; Mayo, B. Antibiotic Susceptibility Profiles of Lactic Acid Bacteria from the Human Vagina and Genetic Basis of Acquired Resistances. Int. J. Mol. Sci. 2020, 21, 2594. [CrossRef] [PubMed]

38. Abdolrasouli, A.; Roushan, A. Corynebacterium propinquum associated with acute, nongonococcal urethritis. Sex Transm. Dis. 2013, 40, 829-831. [CrossRef] [PubMed]

39. Meštrović, T. A microbial game of whack-a-mole: Clinical case series of the urethral uncloaking phenomenon caused by Corynebacterium glucuronolyticum in men treated for Chlamydia trachomatis urethritis. Infection 2019, 47, 121-124. [CrossRef] [PubMed]

40. Barberis, C.M.; Montalvo, E.; Imas, S.; Traglia, G.; Almuzara, M.N.; Rodriguez, C.H.; Famiglietti, A.; Mazzocchi, O.; Vay, C. Total nephrectomy following Corynebacterium coyleae urinary tract infection. JMM Case Rep. 2018, 5, e005149. [CrossRef] [PubMed]

41. Ruiz-García, C.; Muñoz-Hoyos, A.; Lara-Oya, A.; Navarro-Marí, J.M.; Gutiérrez-Fernández, J. Actinotignum induced balanoposthitis in children. A literature review and a case report. An. Pediatr. 2018, 89, 246-248. [CrossRef]

42. Pedersen, H.; Senneby, E.; Rasmussen, M. Clinical and microbiological features of Actinotignum bacteremia: A retrospective observational study of 57 cases. Eur. J. Clin. Microbiol. Infect. Dis. 2017, 36, 791-796. [CrossRef] 
43. Lotte, R.; Lotte, L.; Ruimy, R. Actinotignum schaalii (formerly Actinobaculum schaalii): A newly recognized pathogen-review of the literature. Clin. Microbiol. Infect. 2016, 22, 28-36. [CrossRef]

44. Lara-Oya, A.; Navarro-Marí, J.M.; Gutiérrez-Fernández, J. Actinotignum schaalii (formerly Actinobaculum schaalii): A new cause of balanitis. Med. Clin. 2016, 147, 131-132. [CrossRef]

45. Carrillo-Ávila, J.A.; Bonilla-García, L.; Navarro-Marí, J.M.; Gutiérrez-Fernández, J. The first reported case of pelvic inflammatory disease caused by Actinobaculum massiliense. Anaerobe 2019, 55, 93-95. [CrossRef]

46. Pérez-Torralba, C.; Ruiz-Olivares, M.; Sanbonmatsu-Gámez, S.; Expósito-Ruíz, M.; Navarro-Marí, J.M.; Gutiérrez-Fernández, J. Increased infections by herpes simplex virus type 1 and polymicrobials of the genital tract, in the general population of a Spanish middle city. Rev. Esp. Quimioter. 2021, 34, 320-329. [CrossRef] [PubMed]

47. Artero-López, J.; Gutiérrez-Soto, B.; Expósito-Ruiz, M.; Sorlózano-Puerto, A.; Navarro-Marí, J.M.; Gutiérrez-Fernández, J. Etiology of urinary tract infections in our health area and susceptibility profile of the most common uropathogens. Arch. Esp. Urol. 2021, 74, 197-207. [PubMed] 